\title{
Longitudinal Ultrasonic Vibration Assisted Rapid Solid Phase Bonding of 2024 Aluminum Alloy Using Ag as Interlayer for Structure Lightweight Design
}

\author{
Baoqun Ning ${ }^{1,2} \cdot$ Yong $\mathrm{Nie}^{1} \cdot$ Qian $\mathrm{Wang}^{1} \cdot \mathrm{Yu} \mathrm{Fu}^{1} \cdot \mathrm{Yue} \mathrm{Li}^{1} \cdot$ Jian $\mathrm{Han}^{1} \cdot$ Yingfeng Shao ${ }^{3}$. Jiuchun Yan ${ }^{4}$
}

Received: 14 June 2020 / Accepted: 29 September 2020

(c) The Korean Institute of Metals and Materials 2020

\begin{abstract}
This paper introduced a method of rapid solid-phase bonding Al block with Ag as the intermediate layer by longitudinal ultrasonic vibration under eutectic temperature in the atmospheric environment. This method is suitable for the application of structural lightweight design. It was observed that $\mathrm{Al}$ and $\mathrm{Ag}$ diffuse with each other in the weld seam to form an intermetallic compound $\mathrm{Ag}_{2} \mathrm{Al}$ with close hexagonal structure. The effects of different reaction temperatures and ultrasonic vibration times on the microstructure and mechanical properties of intermetallic compound $\mathrm{Ag}_{2} \mathrm{Al}$ were discussed. The influence of the effect of ultrasonic softening waves on surface oxide film rupture and element diffusion was explored. With the increase of ultrasonic vibration time, the intermetallic compounds grew along with the interface and the thickness increased. When the welding temperature was $500{ }^{\circ} \mathrm{C}$ and the ultrasonic vibration was $20 \mathrm{~s}$, the highest average strength of the welded joint reaches $46.68 \mathrm{MPa}$.
\end{abstract}

Keywords Ultrasound $\cdot$ Aluminum alloy $\cdot$ Intermetallic compound $\cdot$ Solid phase bonding $\cdot$ Microstructure $\cdot$ Mechanical properties

\section{Introduction}

Aluminum alloy has become the most widely used non-ferrous metal structural materials in industrial production [1,2] due to the characteristics of low density, high strength, good plasticity, easy processing, good conductivity, thermal conductivity and so on [3-5]. In the field of electronic products,

Electronic supplementary material The online version of this article (https://doi.org/10.1007/s12540-020-00891-7) contains supplementary material, which is available to authorized users.

Qian Wang

wangqian_tjut@163.com

1 School of Materials Science and Engineering, Tianjin University of Technology, Tianjin 300384, China

2 Tianjin Metal Materials High Efficient and Near Net Shaping Technology Engineering Center, Tianjin 300384, China

3 State Key Laboratory of Nonlinear Mechanics, Institute of Mechanics, Chinese Academy of Sciences, Beijing 100190, China

4 State Key Lab of Advanced Welding and Joining, Harbin Institute of Technology, Harbin 150001, China aerospace, structural lightweight design and other fields [6, 7], aluminum-based materials are needed for low temperature and precise connection. However, due to the isolation of the natural oxide film on the surface of aluminum and the easy heating and softening [8,9], there are some difficulties in connection.

Under the protection of vacuum or inert gas, aluminum alloy soldering [11-13] and diffusion welding [14, 15] can be realized. In order to braze aluminum alloy under atmospheric conditions, flux is usually needed $[16,17]$. Cold forming of aluminum alloy can be realized by rolling welding and crimping in atmosphere [18].

At present, some researches have shown that the connection of aluminum-based materials is realized by ultrasonic assisted brazing $[19,20]$ and ultrasound-induced transient liquid-phase welding [21-23], mainly using the effect of ultrasonic in the liquid phase, under the condition of no flux and atmosphere. Especially in the ultrasound-induced transient liquid-phase welding, plastic deformation occurs due to its acoustic softening effect [24], which makes the oxide film breaks in the solid phase [10,22].

The effect of ultrasonic softening refers to the decrease of the yield strength of the base metal caused by the 
ultrasonic energy transferred to the test piece in the process of ultrasonic welding [25]. The mechanism of acoustic softening is attributed to the volume distortion of ultrasonic energy absorbed by dislocations [26]. At the same time, a large amount of heat energy is generated by the relative friction and plastic deformation of the base metal, which further affects the deformation behavior of the weldment and accelerates the mutual diffusion of elements.

In this experiment, a longitudinal ultrasonic was applied for the first time to connect bulk aluminum-based materials with $\mathrm{Ag}$ as the middle layer under the condition of no liquid-phase solid phase. Al and Ag were connected by diffusion. The time required for welding samples is shortened to $20 \mathrm{~s}$, and the welding efficiency is improved. The effects of temperature and ultrasonic vibration on the microstructure and properties of welded joints were researched. The effects of ultrasonic on the surface oxide film rupture and Ag / Al mutual diffusion were discussed.

Table 1 Mechanical properties of 2024 aluminum alloy

\begin{tabular}{lllll}
\hline $\begin{array}{l}\text { Tensile } \\
\text { strength } \\
(\mathrm{MPa})\end{array}$ & $\begin{array}{l}\text { Yield } \\
\text { strength } \\
(\mathrm{MPa})\end{array}$ & $\begin{array}{l}\text { Fatigue } \\
\text { strength } \\
(\mathrm{MPa})\end{array}$ & $\begin{array}{l}\text { Shear strength } \\
(\mathrm{MPa})\end{array}$ \\
\hline $2024 \mathrm{Al}$ & 470 & 325 & 105 & 285 \\
\hline
\end{tabular}

\section{Materials and Methods}

\subsection{Materials}

In this experiment, 2024Al alloy were purchased as test samples with a size of $10 \mathrm{~mm} \times 10 \mathrm{~mm} \times 5 \mathrm{~mm}$. $\mathrm{Ag}$ foil as interlayer was purchased with a size of $10 \mathrm{~mm} \times 10 \mathrm{~mm} \times 0.05 \mathrm{~mm}$. The mechanical properties of 2024 aluminum alloy are shown in Table 1. Firstly, the samples were polished on $\mathrm{SiC}$ paper of 400 grit, 800 grit, 1500 grit and 2000 grit respectively, and then polished with $\mathrm{Al}_{2} \mathrm{O}_{3}$ polishing agent. After the surface of the samples were polished to mirror shape, the samples were ultrasonically cleaned in alcohol for $15 \mathrm{~min}$ and then dried for standby. The Ag foil was immersed in alcohol to ultrasonic cleaning for $15 \mathrm{~min}$ and dry it for standby.

\subsection{Welding Process}

The schematic diagram of ultrasonic-assisted welding system was shown in Fig. 1a. The ultrasonic-assisted welding system equipped with ultrasonic generator and high-frequency induction heating equipment was used for welding. According to the structure of $\mathrm{Al} / \mathrm{Ag} / \mathrm{Al}$, the sample was vertically placed in a special welding fixture. The ultrasonic indenter was placed on the surface of Al material to provide ultrasonic vibration and welding pressure. During the experiment, thermocouple was used to measure the temperature. When the temperature in muffle furnace reached a
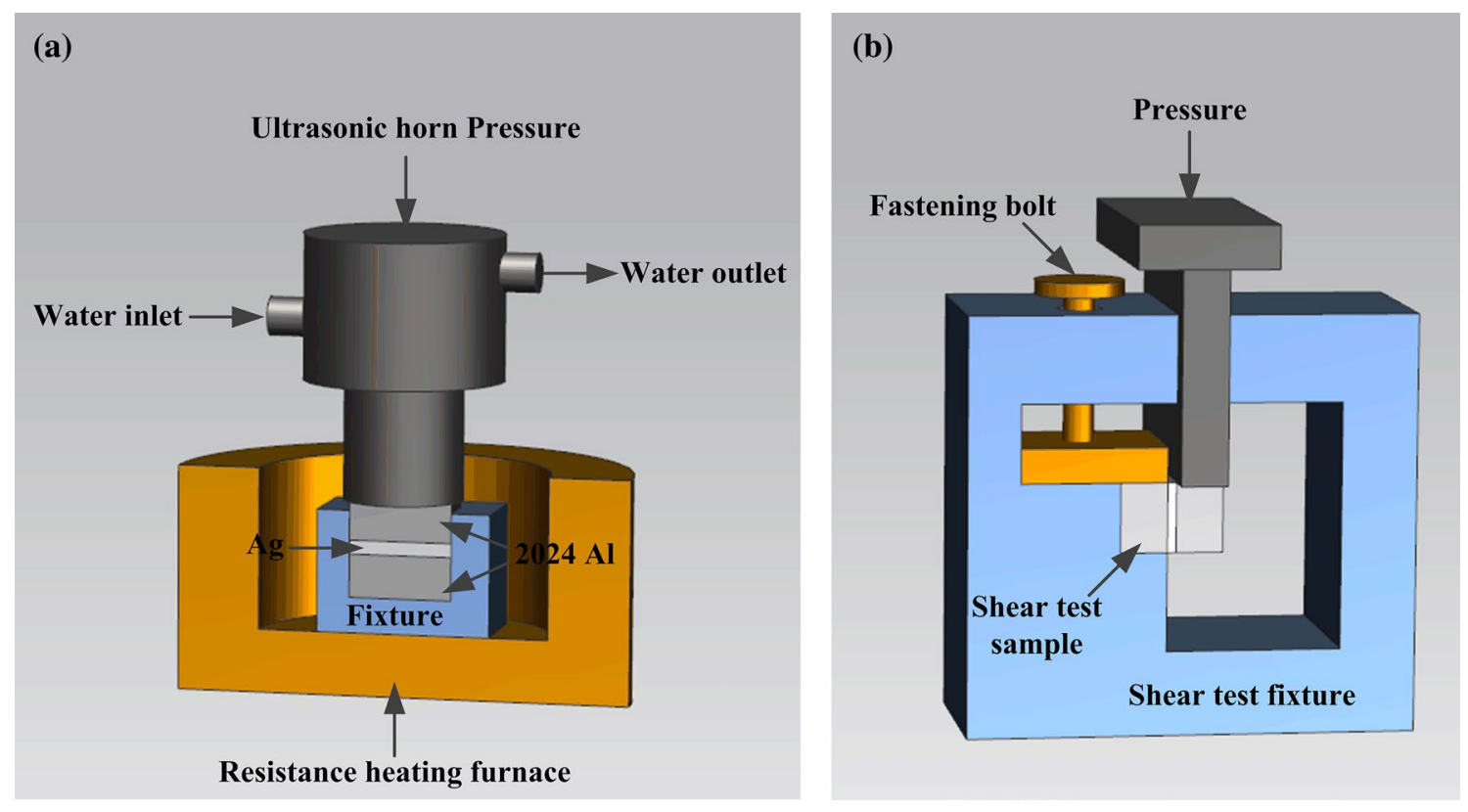

Fig. 1 Schematic diagram of a welding process, $\mathbf{b}$ strength test process 
specific reaction temperature, ultrasonic wave was applied. The welded sample is cooled to room temperature in air. The welding temperature was $500^{\circ} \mathrm{C}$. The ultrasonic action time was $5 \mathrm{~s}, 10 \mathrm{~s}$ and $20 \mathrm{~s}$ respectively. The pressure was $0.1 \mathrm{MPa}$, and the ultrasonic amplitude was $6 \mu \mathrm{m}$.

\subsection{Characterization Test and Observation}

The microstructure and composition of the weld seam were observed and tested by a scanning electron microscope (SEM, ZEISS MERLIN Compact and S-3400) equipped with energy dispersive X-ray spectrometer (EDS) and HighResolution Transmission Electron Microscope with FEG (TEM). The strength was measured by a WDW-D100EIII miniature electronic universal testing machine at a constant speed of $1 \mathrm{~mm} / \mathrm{min}$, the schematic diagram of the strength test process was shown in Fig. 1b. At least three times were carried out under each test condition. The fracture surface was observed by SEM.

\section{Results and Discussion}

\subsection{Description of Experimental Results}

Figure $2 \mathrm{a}-\mathrm{c}$ are microstructure diagrams of the joint obtained at reaction temperature $500{ }^{\circ} \mathrm{C}$ and different ultrasonic vibration times. They were observed that there were no impurities, bubbles and other defects around the weld.

Figure $2 \mathrm{a}$, when ultrasonic vibration for $10 \mathrm{~s}$, uneven thickness and discontinuous gray intermetallic compounds were observed on both sides of the reaction interface. The gray phase formed on the $\mathrm{Ag}$ side was more than that on the $\mathrm{Al}$ side, and the thickest area was about $3 \mu \mathrm{m}$.

Figure $2 b$, when ultrasonic vibration was applied for $10 \mathrm{~s}$, the growth of gray mesophase along the reaction interface had a gradually increasing trend, with the thickest area being about $9 \mu \mathrm{m}$, but during the observation of weld seam, found that the growth was uneven. The reaction interface was enlarged, and it was found that the oxide film was partially ruptured and the elements diffused with each other. Moreover, there was a delamination phenomenon at the reaction interface, and the thickness of the delamination area was uneven, resulting in needle-like substances on the Al-based side and scattered distribution. After material analysis, it was determined that the intermetallic compound $\mathrm{Ag}_{2} \mathrm{Al}$ was generated in the delaminated region.

Figure 2c, when ultrasonic vibration for $20 \mathrm{~s}$, the thickness of the $\mathrm{Ag}_{2} \mathrm{Al}$ layer gradually increased, and the needle-like substances generated on the 2024Al side increased and were more densely distributed.

EDS analysis was carried out on the interface in Fig. 2c. EDS analysis was used to further analyze the distribution and diffusion of elements in the ultrasonic welding process of heterogeneous metals, and the welding seams formed at different welding times were studied and analyzed in turn. It was found that the solid phase diffusion bond between $\mathrm{Ag}$ and $\mathrm{Al}$ was promoted by ultrasonic wave, and $\mathrm{Ag}$ and $\mathrm{Al}$ were diffused through $\mathrm{Al}_{2} \mathrm{O}_{3}$ to form $\mathrm{Ag}_{2} \mathrm{Al}$. It could be seen from Table 2 that sites 1 was solid solutions of ( $\mathrm{Ag}$ ), sites 2, 3 were solid solutions of (Al).
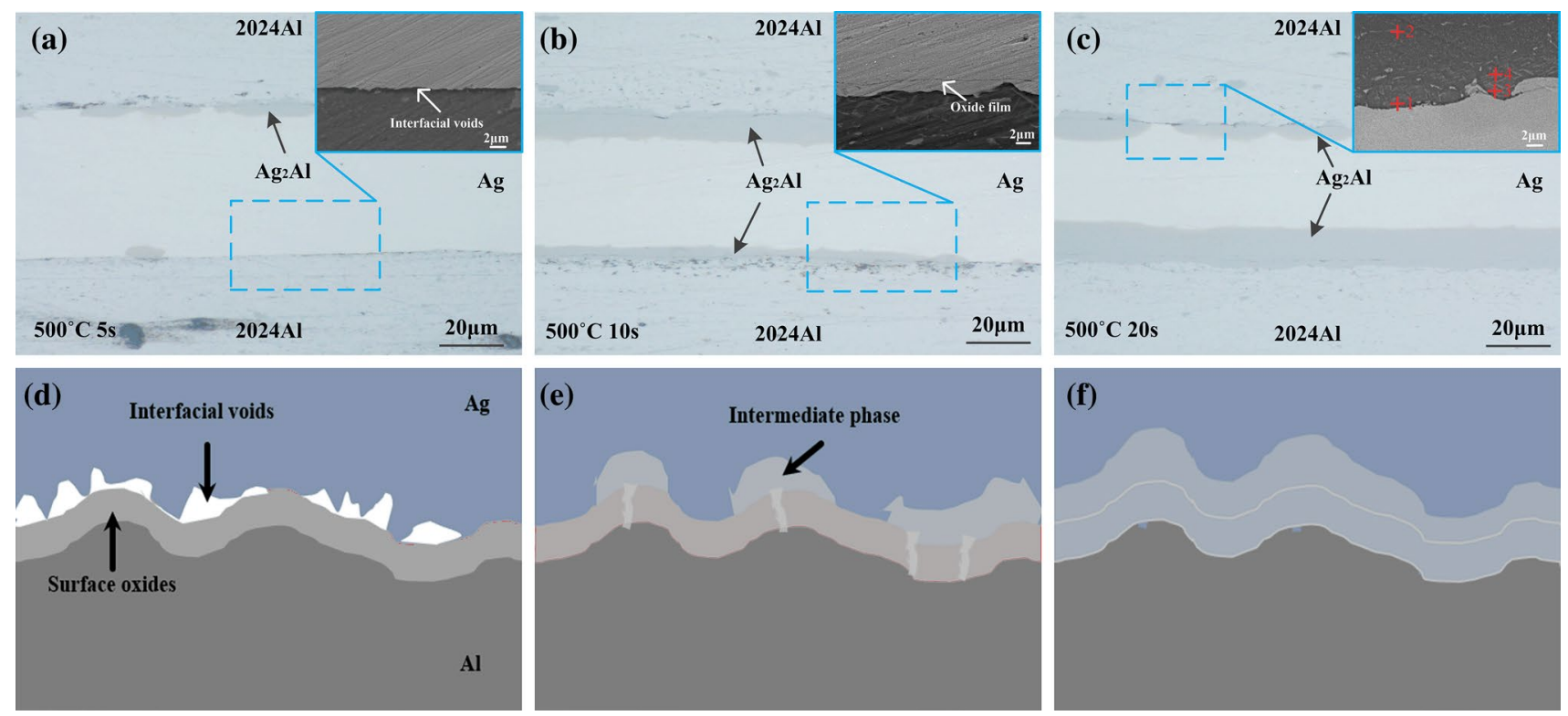

Fig. 2 Microstructure of the joints obtained under different ultrasonic vibration times: a $5 \mathrm{~s}, \mathbf{b} 10 \mathrm{~s}$, c $20 \mathrm{~s}$, and schematic diagram of the bonding process of silver and aluminum: $\mathbf{d}$ before ultrasonic wave, $\mathbf{e}$ cracks appear in the oxide film, $\mathbf{f}$ the oxide film disappears completely 
Table 2 EDS analysis results of points 1 to 4 in Fig. 2c

\begin{tabular}{lll}
\hline Point & $\mathrm{Ag}(\mathrm{at} \%)$ & $\mathrm{Al}(\mathrm{at} \%)$ \\
\hline 1 & 81.63 & 18.37 \\
2 & 58.64 & 41.36 \\
3 & 38.75 & 61.25 \\
4 & 98.80 & 1.20 \\
\hline
\end{tabular}

\subsection{Formation Process of Intermetallic Compounds}

According to the experimental phenomena, the process of ultrasonic assisted solid-state diffusion bonding of $\mathrm{Ag}$ and $\mathrm{Al}$ can be divided into three stages.

In the first stage, the cracks appear in the brittle oxide film, and the base metal $\mathrm{Al}$ to be welded on both sides contacts with the intermediate layer Ag under certain pressure. However, on the micro scale, because the metal surface of $\mathrm{Ag}$ and $\mathrm{Al}$ were not smooth, the contact between the two surfaces were composed of many rough convex contact points, as shown in Fig. 2d. When high-frequency mechanical wave causes plastic deformation of materials [26], cracks are more likely to occur in the brittle oxide films due to the physical differences between the oxide films and the internal pure metals. With the ultrasonic energy softens, the metal gradually softens and plastic deformation occurs [27, 28], and the energy transfer in the material changes with the relaxation of grain boundary [18, 29].

In the second stage, when the welding time increased, the real contact area of $\mathrm{Ag}$ and $\mathrm{Al}$ increased and the interface gap decreased. As shown in Fig. 2e, the pure metal $\mathrm{Al}$ exposed in the second stage gradually diffused to $\mathrm{Ag}$, resulting in solid solution based on $(\mathrm{Ag})$ and $(\mathrm{Al})$ and three intermediate phases $\delta, \beta$ and $\mu$. The formation of these three intermediate phases stems from the relative valency effect in Hume-Rothery principle [30].

In the third stage, a stable connection was formed. As shown in Fig. 2f, $\mathrm{Ag}$ and the oxide film at the $\mathrm{Al}$ interface were in close contact with each other to break the internal metal, forming a solid metal bond.

\subsection{Performance Testing and Fracture Analysis}

Figure 3a shows the shear strength test results of the joint. It could be seen that the shear strength of the joint increases with the increase of ultrasonic vibration time. The highest average strength of samples was $46.67 \mathrm{MPa}$ at $20 \mathrm{~s}$. Fu et al. [31] obtained the silver aluminum joint with shear strength of 28.0 MPa by diffusion welding in a vacuum environment of $450{ }^{\circ} \mathrm{C} 13.33 \mathrm{~Pa}$. Compared with it, it was obvious that the welding time could be effectively reduced from $10 \mathrm{~min}$ to $20 \mathrm{~s}$ by introducing ultrasonic waves, and the applied pressure could be reduced from 6.89 to $0.1 \mathrm{MPa}$. The results showed that ultrasonic vibration could promote the mutual diffusion of elements, and the thickness of $\mathrm{Ag}_{2} \mathrm{Al}$ layer increased, which could strengthen the mechanical properties of the joint. Figure $3 b$ shows the fracture morphology of ultrasonic vibration $20 \mathrm{~s}$ joint. It could be seen that the fracture was mostly lamellar fracture with crater structure. The fracture surface is analyzed by XRD, and the results are shown in Fig. 3c. It could be seen that there was an intermetallic compound $\mathrm{Ag}_{2} \mathrm{Al}$ in the fracture surface.

Figure 4 shows the fracture morphology and EDS analysis under different ultrasonic time. Figure $4 a-c$ show that the section was relatively flat without large fluctuation. With the increase of ultrasonic time, pit structure appears near the fracture line. In order to more clearly analyze the changes of various metal structures in the weld, the linear scanning of the welds with different welding time was carried out by EDS energy spectrum. From the corresponding element distribution curve, could see that there were some changes in the interface of $\mathrm{Ag}$ and $\mathrm{Al}$. The results show that the diffusion of atoms occurred at the interface, part of $\mathrm{Ag}$ atoms flow to the $\mathrm{Al}$ blocks on both sides, and some $\mathrm{Al}$ atoms diffused into the interlayer. It could be seen from Fig. 4f that the diffusion depth of $\mathrm{Ag}$ atom was significantly greater than that of $\mathrm{Al}$ atom. Consistent with the above experimental results, the solid diffusion bonding of $\mathrm{Ag}$ and $\mathrm{Al}$ was promoted by ultrasonic wave.

\section{Discussion}

As shown in Fig. 3d Al-Ag binary phase diagram, the maximum solubility of $\mathrm{Al}$ in $\mathrm{Ag}$ is $20.4 \%$ (at) at $450{ }^{\circ} \mathrm{C}$, and the peritectoid transformation takes place [32] $(\mathrm{Ag})+\delta \rightleftharpoons \mu$. In the face-centered cubic $\mathrm{Al}$ matrix, the $\mathrm{Ag}_{2} \mathrm{Al}$ with hexagonal close-packed structure is precipitated, although the atomic radius of $\mathrm{Ag}$ and $\mathrm{Al}$ are similar $(\mathrm{Ag}$ is $144 \mathrm{pm}, \mathrm{Al}$ is $143 \mathrm{pm}$ ) and both of them are face-centered cubic structure, but they can not form infinite solid solutions. This is due to the relative valency effect in the Hume-Rothery principle. There is a certain difference between the solubility of highpriced component and low-priced component, which leads to the fact that $\mathrm{Ag}$ and $\mathrm{Al}$ cannot form a continuous solid solution [32]. The VEC (Valency Effect Concentration) is an important factor affecting the solubility limit.

The stacking order of $\mathrm{Ag}$ and $\mathrm{Al}$ in face-centered cubic structure is $\mathrm{ABCABC}$, while the stacking order of $\mathrm{Ag}_{2} \mathrm{Al}$ hexagonal close-packed structure is ABABAB [33], so it is not difficult to can the slip change of atomic layer.

Ultrasonic assisted solid-state diffusion bonding can also be expressed in a certain way as the relationship between the cyclic stress with high frequency alternating and the strain in the material under certain temperature and pressure fields.

According to the generalized Hooke's law [29], it is pointed out that the relationship between stress and strain 
(a)

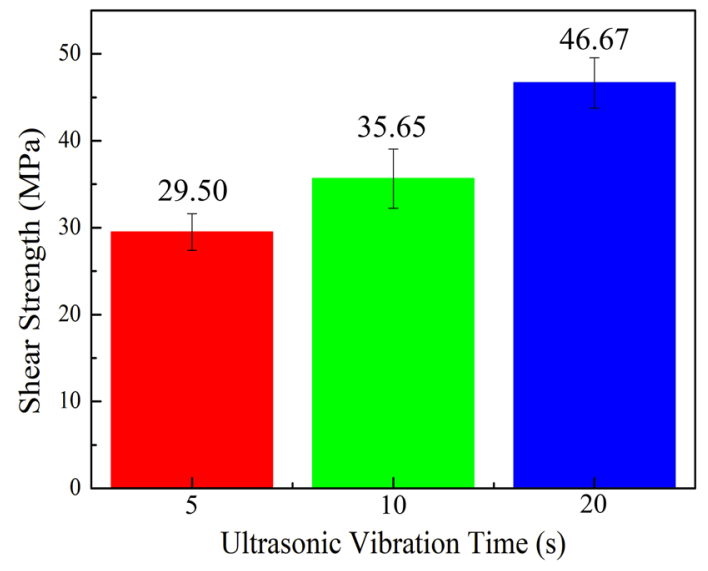

(c)

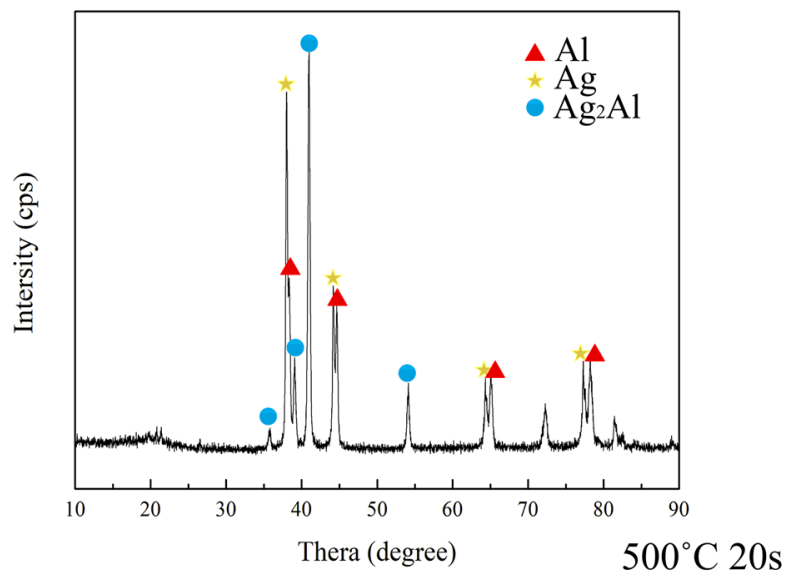

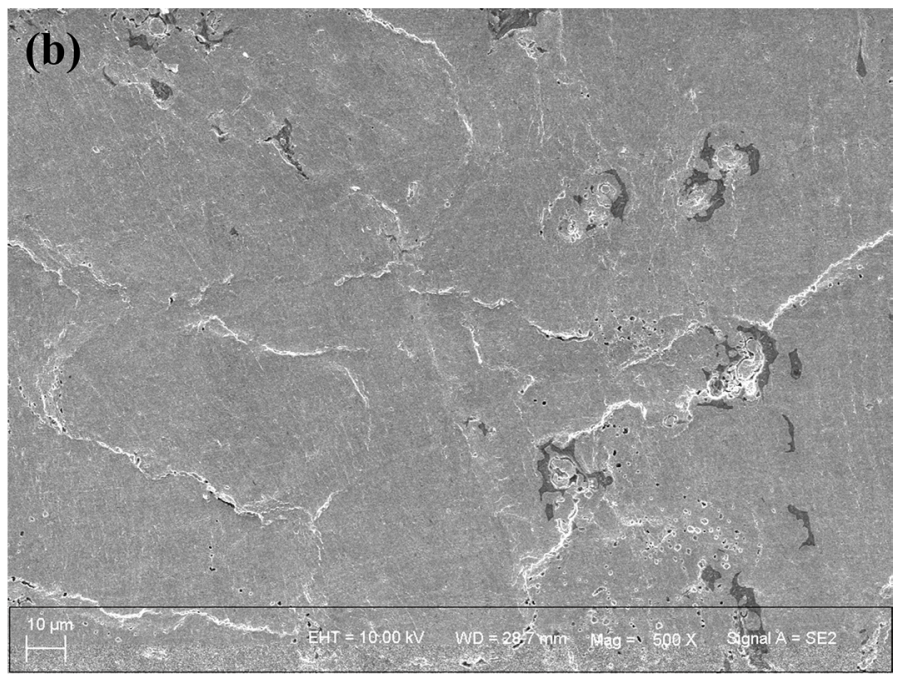

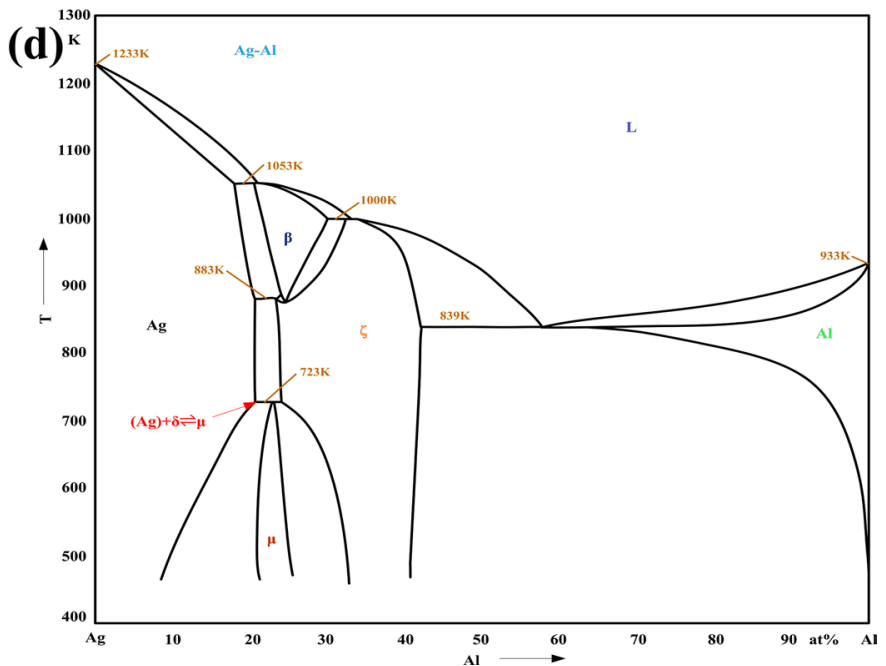

Fig. 3 a The diagram of shear strength, $\mathbf{b}$ fracture morphology of joint under ultrasonic vibration for $20 \mathrm{~s}$, $\mathbf{c}$ XRD analysis was carried out on the fracture of the sample obtained under ultrasonic vibration for $20 \mathrm{~s}, \mathbf{d}$ Al-Ag binary phase diagram

is in direct proportion in general elastomer, that is, the applied stress and the generated strain are linearly varying. The generation of interface deformation and diffusion is nothing more than the movement of atoms from one equilibrium position to another in the microscopic mechanism, and this process needs to cross a certain barrier, that is, a certain activation energy.

When the object vibrates, it will cause the energy consumption in the material, that is, internal friction [29]. The consumption here means a kind of energy conversion. According to the experimental results, the internal friction of the material is not only related to the material internal but also affected by many external factors, including the amplitude, frequency and temperature field of the load vibration, etc.
When the ultrasonic wave acted on the material, the internal friction would increase, which was the process of increasing activation energy. In the Fig. 5, the applied ultrasonic energy field had a certain impact on the original relatively stable state of the metal. At the same time, the internal structure would soften after ultrasonic passing through the material, that is, the acoustic softening mechanism [34]. It is generally believed that the mechanism of acoustic softening is due to the volume distortion of ultrasonic energy absorbed by dislocation $[35,36]$.

From the microscopic point of view, friction is caused by repeated contact movement between surface micro convex bodies. Its main functions include destroying and removing surface oxides and enhancing acoustic softening mechanism. On the other hand, the ultrasonic generator will produce 

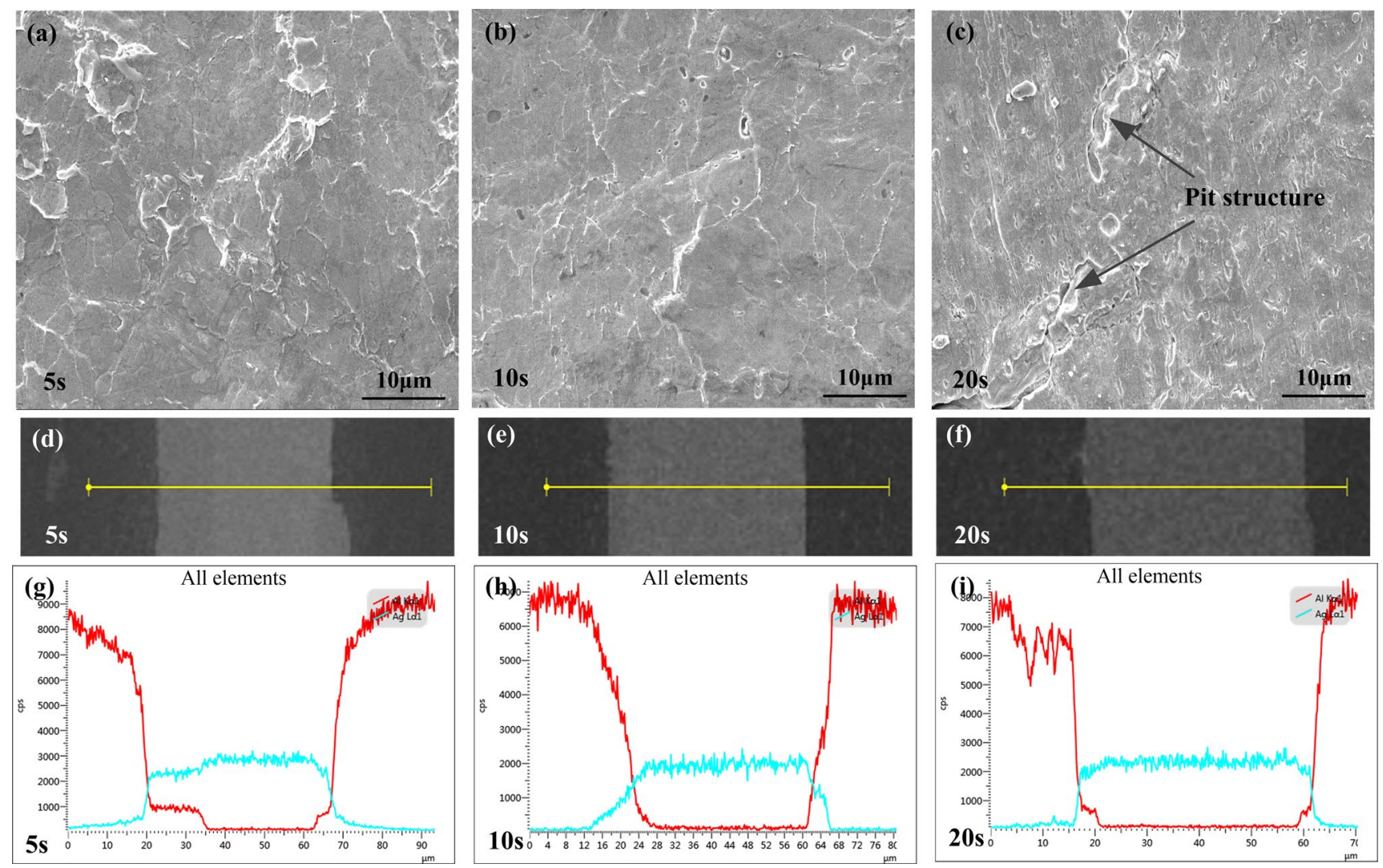

Fig. 4 fracture morphology of joint under ultrasonic vibration for a 5 s, b 10 s, c 20 s, EDS analysis location: d 5 s, e 10 s, f 20 s, EDS analysis results of $\mathbf{g} 5 \mathrm{~s}, \mathbf{h} 10 \mathrm{~s}, \mathbf{i} 20 \mathrm{~s}$

Fig. 5 contact diagram of metal surface in micro state: a ultrasonic energy field without load, b ultrasonic energy field with load (a)

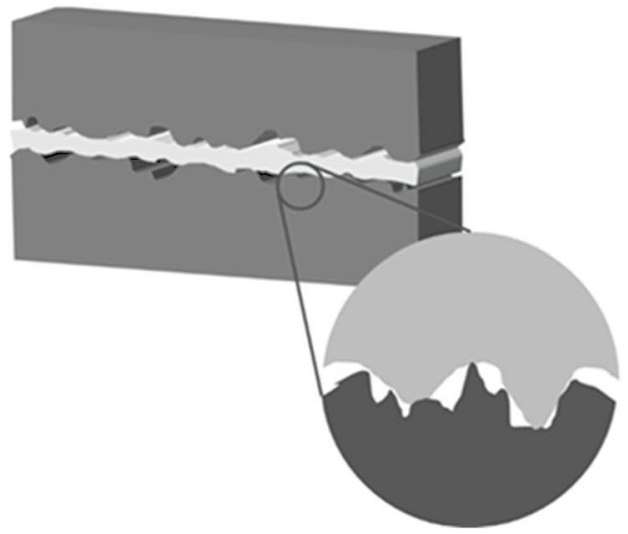

(b)

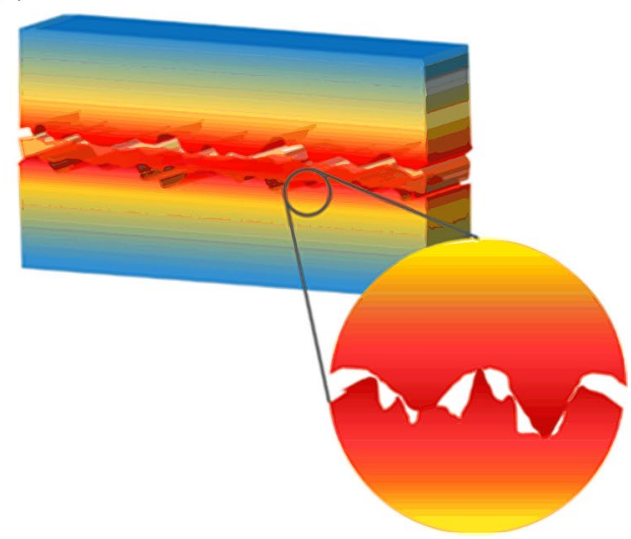

high-frequency mechanical vibration, and plastic deformation will occur in the material with high strain rate [37]. In the welding process, under the action of friction heat and ultrasonic energy, the weldment material softens gradually, and the plastic deformation area increases gradually. Plastic deformation promotes the bonding between contact interfaces [25, 27, 28, 37, 38].

Gunduz et al.[39] found that the alternating ultrasonic stress and quasi-static pressure are superposed, which results in the reduction of the real stress required for the instantaneous plastic flow in the process of stress application. The ultrasonic energy field will increase the vacancy concentration [39] caused by some dislocations, as shown in the Fig. 6. And increase the strain energy of dislocations, resulting in the movement of extended dislocations. At the same time, a part of ultrasonic energy is absorbed by dislocation, which increases the potential energy of 
Fig. 6 a the diagram of metal atom arrangement with normal unloaded ultrasonic energy field, $\mathbf{b}$ the diagram of vacancy concentration increases after loading ultrasonic energy field (a)

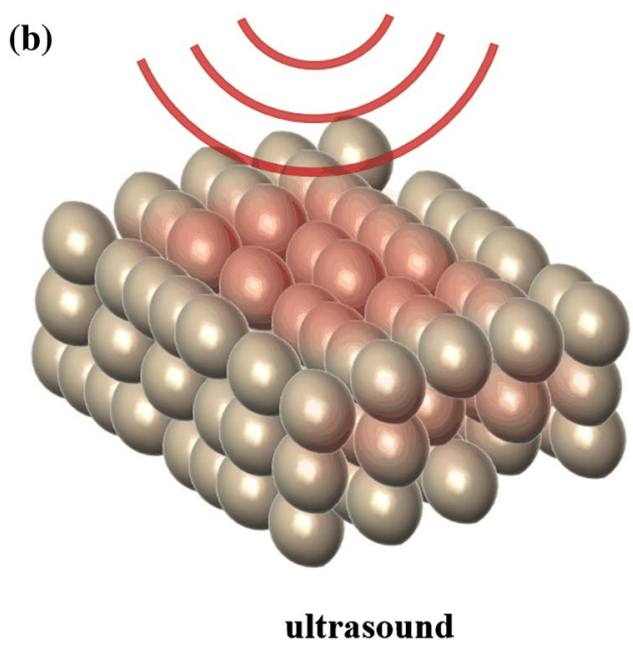

dislocation line, and it is easier to interact with other defects to produce plastic deformation.

As shown in Fig. 7, the TEM diagram of the contact interface between $2024 \mathrm{Al}$ and $\mathrm{Ag}_{2} \mathrm{Al}$ is shown. The pattern of HR-TEM was analyzed by inverse fast Fourier transforms (FFT) [40-42], and the results are as shown in Fig. 7b, c. From the subset of Fig. 7b, c, it is obvious that there are a lot of dislocations at the interface. Under the action of shear stress, dislocations slip along the slip surface. At this time, a large number of dislocations accumulated at the interface slip simultaneously, and plastic deformation occurs at the interface.
Fig. 7 a TEM diagram of 2024Al and $\mathrm{Ag}_{2} \mathrm{Al}$ interface, b, $\mathbf{c}$ inverse Fourier diagram at interface
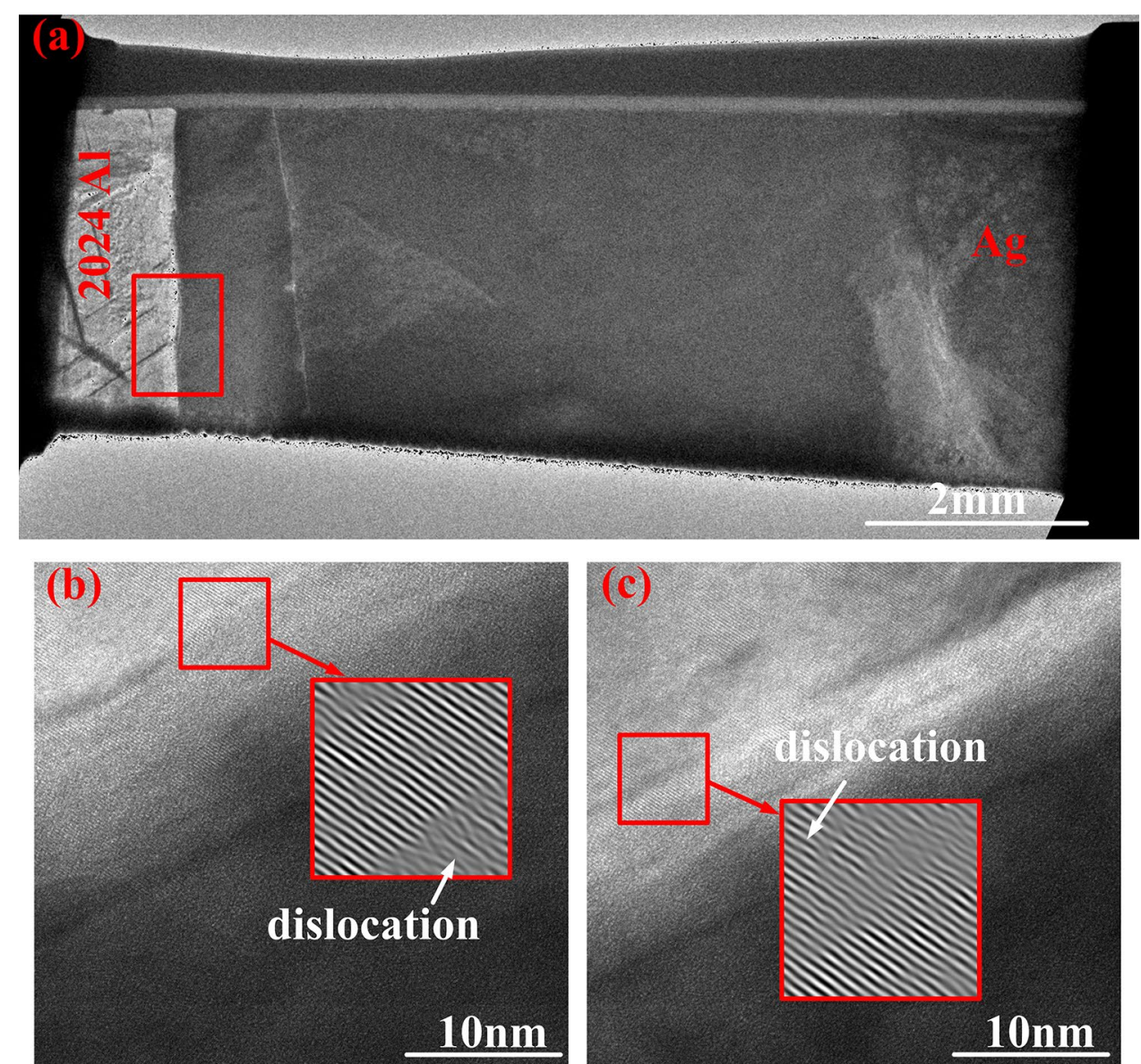


\section{Conclusion}

In this paper, we use ultrasonic wave to promote the element diffusion between $\mathrm{Ag}$ and $\mathrm{Al}$ solid phase in the atmospheric environment, and produce the intermetallic chemical $\mathrm{Ag}_{2} \mathrm{Al}$ with dense hexagonal structure. The experimental results are as follows:

1. When the temperature is lower than the eutectic temperature of $\mathrm{Ag}$ and $\mathrm{Al}$, under the influence of ultrasonic wave, temperature field and stress field, the oxide film of the base metal is broken rapidly, the mutual diffusion of elements is accelerated, and the effective connection is formed.

2. When the reaction temperature was $500{ }^{\circ} \mathrm{C}$, the ultrasonic vibration lasted only $5 \mathrm{~s}$, forming a rapid bonding.

3. During the experiment, the peritectic reaction $(\mathrm{Ag})+\delta \rightleftharpoons \mu$ took place, forming a dense hexagonal structure of $\mathrm{Ag}_{2} \mathrm{Al}$.

4. With the increase of ultrasonic vibration time, the $\mathrm{Ag}_{2} \mathrm{Al}$ formed and the shear strength of welded joint increased.

5. When the ultrasonic vibration is $20 \mathrm{~s}$, the average shear strength of the welded joint reaches the maximum value of $46.67 \mathrm{MPa}$.

Acknowledgements This research was sponsored by the National Natural Science Foundation of China (Grant No. 51504165), the Tianjin Sci. \& Tec. Project (Grant No. 16JCQNJC02600).

Data Availability All data generated or used during the study appear in the submitted article.

\section{Compliance with Ethical Standards}

Conflict of interest No conflict of interest exits in the submission of this manuscript, and manuscript is approved by all authors for publication. I would like to declare on behalf of my co-authors that the work described was original research that has not been published previously, and not under consideration for publication elsewhere, in whole or in part. All the authors listed have approved the manuscript that is enclosed.

\section{References}

1. P. Chai, Y. Wang, Met. Mater. Int. 25, 1574 (2019)

2. J.S. Kim, J. Park, K.S. Lee, S. Lee, Y.W. Chang, Met. Mater. Int. 22, 771 (2016)

3. D.S. Wong, P. Lavoie, JOM 71, 2926 (2019)

4. W.X. Yang, Y. Yuan, G.Y. Liu, B. Zhang, R.K. Yang, Mater. Lett. 226, 4 (2018)

5. S.A. Anggraini, M. Uehara, H. Yamada, M. Akiyama, Mater. Lett. 219, 247 (2018)

6. R.S. Long, E. Boettcher, D. Crawford, JOM 69, 2635 (2017)

7. H.H. Li, Z.L. Hu, W.Z. Hu, L. Hua, JOM 71, 1687 (2019)

8. Q. Wang, X.G. Chen, L. Zhu, J.C. Yan, Z.W. Lai, P.Z. Zhao, J.C. Bao, G.C. Lv, C. You, X.Y. Zhou, J. Zhang, Y.T. Li, Ultrason. Sonochem. 34, 947 (2017)
9. L. Shi, J.C. Yan, B. Peng, Y.F. Han, Mater. Sci. Eng. A 528, 7084 (2011)

10. Z.W. Xu, J.C. Yan, B.Y. Zhang, X.L. Kong, S.Q. Yang, Mater. Sci. Eng. A 415, 80 (2006)

11. Z.W. Niu, Z. Ye, J.H. Huang, H. Yang, J. Yang, S.H. Chen, Mater. Charact. 138, 78 (2018)

12. S.P. Hu, C.N. Niu, H. Bian, X.G. Song, J. Cao, D.Y. Tang, Mater. Lett. 218, 86 (2018)

13. J.M. Shi, Q. Wang, X.Y. Tian, J.L. Li, L.X. Zhang, J. Manuf. Process. 47, 211 (2019)

14. M.S. Kenevisi, S.M. Mousavi Khoie, Mater. Lett. 76, 144 (2012)

15. J. Wang, Y.J. Li, H.J. Ma, Vacuum 79, 45 (2005)

16. Z.W. Niu, J.H. Huang, K.K. Liu, F.Z. Xu, S.H. Chen, X.K. Zhao, Mater. Lett. 179, 47 (2016)

17. W.L. Wang, Y.C. Tsai, Mater. Charact. 68, 42 (2012)

18. M.H. Vini, O.H. Zadeh, Int. J. Mater. Res. 109, 42 (2018)

19. H.F. Yang, Q. Tan, H.J. Ji, Z.H. Wang, W.F. Xu, M.Y. Li, Mater. Lett. 252, 103 (2019)

20. C. Xu, Q. Lang, Q. Wang, Y.R. Chen, J.C. Yan, S.Y. Chen, JOM 71, 2025 (2019)

21. Q. Wang, Y. Fu, Q. Lang, J.C. Yan, S.Y. Chen, Mater. Lett. 237, 37 (2019)

22. L. Zhu, Q. Wang, L. Shi, X. Zhang, T.H. Yang, J.C. Yan, X.Y. Zhou, Mater. Sci. Eng. A 711, 94 (2018)

23. S. Roh, C. Lee, Met. Mater. Int. 25, 425 (2019)

24. K.K. Chen, Y.S. Zhang, H.Z. Wang, Ultrasonics 75, 9 (2017)

25. J. Hu, T. Shimizu, T. Yoshino, T. Shiratori, M. Yang, Ultrasonics 107, 106107 (2020)

26. T.R. Bieler, A.K. Mukherjee, Mater. Trans. JIM 128, 171 (1991)

27. Z.H. Yao, G.Y. Kim, Z.H. Wang, L.A. Faidley, Q.Z. Zou, D.Q. Mei, Z.C. Chen, Int. J. Plast. 39, 75 (2012)

28. A.V. Kozlov, S.I. Selitser, Mater. Sci. Eng. A 131, 17 (1991)

29. T.S. Ge, Acta Metall. Sin. 33, 9 (1997)

30. M. Stiehler, U. Giegengack, J. Barzola-Quiquia, J. Rauchhaupt, S. Schulze, P. Haussler, J. Phys. Chem. Sol. 68, 1244 (2007)

31. S.W. Fu, C.C. Lee, Mater. Sci. Eng. A 722, 160 (2018)

32. S.S. Lim, P.L. Rossiter, J.E. Tibballs, Calphad 19, 131 (1995)

33. Z.Z. Zhang, J.M. Rosalie, N.V. Medhekar, L. Bourgeois, Acta Mater. 174, 116 (2019)

34. A.A. Ward, Y.B. Zhang, Z.C. Cordero, Acta Mater. 159, 393 (2018)

35. R.T. Murzaev, D.V. Bachurin, A.A. Nazarov, Phys. Met. Metallogr. 118, 621 (2017)

36. S. Najafi, A.R. Eivani, M. Samaee, H.R. Jafarian, J. Zhou, Mater. Charact. 136, 60 (2018)

37. M. Mayer, R. Schwizer, in Proceedings of the 5th Electronics Packaging Technology Conference, EPTC 2003. Singapore, December 10-12, 2003. Thermosonic ball bonding model based on ultrasonic friction power (IEEE, Piscataway, NJ, 2003), pp.738-743

38. K.K. Chen, Y.S. Zhang, H.Z. Wang, Sci. Technol. Weld. Join. 22, 208 (2017)

39. I.E. Gunduz, T.C. Ando, E. Shattuck, P.Y. Wong, C.C. Doumanidis, Scripta Mater. 52, 939 (2005)

40. N. Li, J. Wang, J.Y. Huang, A. Mistra, X. Zhang, Scripta Mater. 63, 363 (2010)

41. J. Wang, A. Misra, Curr. Opin. Solid State Mater. 15, 20 (2011)

42. Z.D. Kou, Y.Q. Yang, L.X. Yang, B. Huang, Y.X. Chen, X. Luo, Mater. Sci. Eng. A 729, 125 (2018)

Publisher's Note Springer Nature remains neutral with regard to jurisdictional claims in published maps and institutional affiliations. 